The Implications of Organizational Learning for Organizational Communication: A Review and Reformulation

\author{
Craig C. Lundberg* \\ Cornell University \\ Judi Brownell \\ Cornell University
}

March 3,1992

Biographical Note

*Corresponding author:

Craig C. Lundberg

School of Hotel Administration

Cornell University

Ithaca, NY 14853-6901

Phone/Fax: 607-255-8361/4179

Dr. Lundberg is the Blanchard Professor of Human Resources Management at the School of Hotel Administration, Cornell University. He is a Fellow of the Academy of Management, the editor of the essay section of the Journal of Management Inquiry, and an active contributor to the field of organizational change, design, and culture, among others.

Judi Brownell is an associate professor of managerial communication at the School of Hotel Administration, Cornell University. She is co-author of Organizational communication and behavior: Communicating for improved performance, and author of Building active listening skills. She is on the editorial board of three communication journals, and has published articles on such topics as organizational transition, managerial listening behavior, organizational communication assessment, and crosscultural communication. 


\begin{abstract}
This manuscript explores the contributions of organizational learning to organizational communication. The study of organizational communication is seen in multi-dimensional terms as the study of how meanings are created, stored, distributed, and modified in the service of organizational performance and change. An overview of organizational communication is provided and organizational learning and its main assumptions are explained. The authors then demonstrate how the incorporation of organizational learning concepts into organizational communication theory permit the integration and extension of much of what is known about how organizational members communicate, learn, and change. An integrative model is presented which explains how individual and organizational understandings are interrelated.
\end{abstract}


The Implications of Organizational Learning for Organizational Communication: A Review and Reformulation

Communication plays an important role in the process of organizational maintenance and change. To better understand this process, we seek conceptual models that provide new and broader perspectives. This search draws attention to the recent work in organizational culture and especially the emerging field of organizational learning (Fiol \& Lyles, 1985; Lundberg, 1989; Levitt \& March, 1988). Organizational learning is a dynamic, process-oriented perspective that focuses our attention on the cultural aspects of communication and, especially, on the processes through which meanings are created and shared.

Organizational learning contributes to organizational communication by providing a link between individuals' communicative behaviors and organizational performance. It also provides an integrative model that explains how individual and organizational understandings are interrelated.

Not only have few communication theorists incorporated organizational change processes into their models (among the exceptions are Huseman, Hayes, \& Alexander, 1977; Jackson, 1985; Susman \& Evered, 1978), but there seems at the moment to be no integrated theory of organizational communication that brings together divergent viewpoints or links the various levels (individual, team, department, organization, etc.) of organizational analysis. Although a variety of mini-theories (Dansereau \& Markham, 1987; Putnam \& Poole, 1987) have been useful in drawing our attention to the unique aspects of various communication contexts and events, such focused perspectives have seldom linked individual performances to broader organizational concerns.

The value of organizational learning, then, may be in providing a framework that integrates individual and organizational levels of analysis and in extending our understanding of how organizational communication contributes to evolutionary organizational changes. Our premise is that the study of organizational communication can be seen as the study of how meanings are created, stored, distributed, and modified in the service of organizational performance and change. This perspective encourages us to understand organizational communication in more holistic, multi-dimensional terms.

This article briefly traces the development of organizational communication, focusing on the symbolic/cultural approach to understanding organizational processes. Next, we discuss organizational learning, noting its main assumptions and discussing how the integration of organizational learning concepts into organizational communication theory permits a broader understanding of how organizational members communicate, learn, and change. Ultimately, we argue that an organizational communication perspective that takes its direction from organizational learning may provide insight into how communicative behaviors at the individual level affect and are affected by larger organizational processes. 


\section{A Framework for Organizational Communication}

There seems to be no single definition of organizational communication (Redding \& Tompkins, 1988). Goldhaber (1983) proposes that organizational communication involves the concepts of process, meaning, message, network, relationship, environment, and uncertainty. Organizational communication, according to Goldhaber, influences and is influenced by its environment; it involves the creation and maintenance of meaning; it involves message flow, people and their relationships, attitudes, feelings, and skills. Yet, in spite of the realization that organizational communication must consider such questions as the relationship of individual communication to organizational performance or the organization's relationship with its environment, no widely-accepted integrative framework has yet been proposed.

The difficulties involved in defining organizational communication processes have resulted in the emergence of several distinct approaches and a variety of research objectives and methods. Although internally consistent, each framework addresses only a portion of the larger question: How does communication within the organization affect larger issues of ongoing organizational performance, adaptation, change, and ultimately survival?

The concerns of organizational communication have paralleled closely the dominant approach to understanding organizations through successive develop mental periods. These approaches include, among others, the rational (Weber, 1947), human resources (Likert, 1961; Argyris, 1970; McGregor, 1960), systems and organizational network (Roberts \& O'Reilly, 1978; Katz \& Kahn, 1966; Rapa- port, 1970; Wigand, 1979; Lawrence \& Lorsch, 1967), and political (V. Schein, 1977, 1985; Pettigrew, 1975; Bolman \& Deal, 1984) perspectives. Although each approach has been useful in highlighting various aspects of organizational life, our interest in organizational learning draws our attention to what has been termed by organizational theorists as the symbolic/cultural frame (Deal \& Kennedy, 1982; Smircich, 1983; Barnett, 1988; E. Schein, 1985).

\section{The Symbolic/Cultural Perspective}

As yet, no one perspective has fully explained how organizational members come to share certain views of the world, why organizational members perceive events in a similar manner, or how they are able to align their activities in order to accomplish individual and organizational tasks. Of all the approaches to understanding organizations, the symbolic/cultural comes closest to addressing these concerns (Putnam \& Pacanowsky, 1983; E. Schein, 1985). Eisenberg and Riley (1988) explain: Communication ... is not a process that takes place in organizations, it is the constitutive means by which organizing occurs (p. 132). 
It is through the use of symbolic action-what we will later simply refer to as communication - that organizational members create, maintain, and change their realities. Social reality is constructed through human interaction. Communication becomes the sense-making process through which individuals make organizational life meaningful. The meaning that something has for one member grows out of the ways in which other organizational members act toward that idea, object, or event. Meanings, then, are social products. Hence, the greater the number of shared experiences organizational members have, the more likely it is that they will assign similar meanings to the actions and events they observe. As members create commonly held assumptions and understandings, they are also more likely to make similar predictions about the kind of response others will make to their behavior.

Through repeated shared experiences, common meanings develop, common assumptions are made, and the foundation of organizational culture is laid. Culture influences organizational members' behavior as it is itself created through employees' interactions. The symbolic/cultural perspective, with its focus on shared meanings, becomes the focal point for our subsequent discussions and is an essential component upon which we build our multi-level model of organizational communication. Symboliccultural theorists (Thayer, 1968; E. Schein, 1985; Pacanowsky \& O'Connell-Trujillo, 1982), then, suggest that organizations cannot be completely structured or "controlled." Organizations are in a constant process of self-organizing or self-designing (Weick, 1979) as individuals engage in symbolic interactions.

\section{Toward an Integrated Theory of Organizational Communication}

Although the symbolic/cultural theorists have moved us substantially closer to an integrated view of organizational communication processes, there is still much work yet to be accomplished. Too little is known about the relationship between symbolic processes and macro-organizational concerns or the impact individuals' interactions have on organizational culture and change. These are precisely where organizational learning may lend organizational communication theorists potentially valuable insight.

The call for a dynamic, integrated theory of organizational communication is clear. To date, no unified model bridges the various levels of organizational communication, from intrapersonal communication to individual behavior, to small groups, to departments, to the organization itself, and beyond to even more encompassing social systems. Nor is there one approach that satisfactorily explains how human communicative behavior affects organizational performance. The focus on predominantly internal communication processes has only occasionally led theorists to link these practices to the larger question of how the organization responds and adapts to its external environment.

Although the symbolic/cultural perspective appears to be a promising starting point, we suggest that a reformulation of organizational communication which includes 
central concepts from the emerging field of organizational learning may enrich our conceptualization. Organizational communication, we argue, concerns those activities and devices which generate, share, and modify meanings associated with organizational performance, maintenance, and change.

The following section introduces organizational learning by describing its assumptions and emerging concepts. The symbolic/cultural view of organizational communication is thus placed into an organizational learning framework, revealing the implications of communicative behavior both at individual and organizational levels.

\section{On Organizational Learning}

Three fundamental tasks face all modem organizations. These are: (1) managing their internal affairs, (2) responding to and surviving in their external environments, and (3) anticipating and preparing for their probable future (Lundberg, 1989). To date, organizational communication has been primarily concerned with the first of these tasks.

Managing internal operations requires that individuals continuously make internal adjustments to ensure that organizational rules and policies are followed. Internal adjustments tend to be based upon the organization's resource allocation and the specific skills of its members. These factors often determine whether organizational goals are achieved. The second fundamental task is environmental survival, which requires adaptation. All organizations are environmentally dependent-for resources, for markets, for satisfying their external constituencies. As environments have become increasingly complex and ambiguous, organizational adaptation through continuous realignment has become a major managerial concern. It is no surprise, therefore, that scanning the environment has become a commonplace activity and that a strategic orientation has become the sine qud non of survival. The third organizational task, to anticipate the future, is a consequence of increasing environmental complexity, interdependence, and turbulence. These three fundamental organizational tasks (adjusting, adapting, and anticipating) each requires that the organization develop the capacity to learn.

\section{Toward a Definition of Organizational Learning}

Simon (1969) defined organizational learning as the growing insights and successful restructuring of organizational problems by individuals reflected in the structural elements and outcomes of the organization itself. This definition, awkwardly, combines some things not easily seen (changes in states of knowledge) with those that are more visible (organizational outcomes). Subsequent theorists have gone on to refer to organizational learning as either new insights or knowledge (Argyris \& Schdn, 1978; Hedberg, 1981) or new structures (Chandler, 1962) or systems (Jelinek, 1979; Miles, 1982), or some combination of these (Shrivastava \& Mitroff, 1982; Bartunek, 1984). These processes have been variously labeled, learning (Cyert \& March, 1963; Jelinek, 1979) to unlearning (Starbuck, Greve, \& Hedberg, 1978), as well as change (Mintzberg 
\& Waters, 1982; Dutton \& Duncan, 1983) and adaptation (Meyer, 1982; Chakravarthy, 1982). The few examples of major research on organizational learning have focused on concerns such as strategy (Miles \& Snow, 1978), innovations (Jelinek, 1979), and decisions (Duncan, 1974; Shrivastava, 1981).

Although there is considerable divergence with regard to how organizational learning is conceptualized, there are several areas of growing agreement. One is that organizational learning is distinct from individual learning; that is, it is more than the sum of each member's learning. Though individual learning is important to organizations, organizations appear to develop and institutionalize systems for influencing their members and for building widespread understandings of both internal and external events. A second area of agreement concerns the importance of the organization's relationship to the parts of the larger environments with which it interacts. If we accept that there is an ongoing process of environmental alignment, we imply that the organization has the capacity to unlearn and relearn based upon past performance and forecasted changes. This more or less continuous realignment is, of course, the essence of strategic adaptation. Realignment always involves choices and these lead organizations to develop the capacity to learn over time (Miles, 1982). For example, all organizational activities will be affected by the decision to sell and distribute a product overseas.

A third area of agreement is that organizational learning is affected by four major factors: the degree of turbulence in the environment, the rigidity of the organization's structure, the adequacy of the organization's strategy, and the "strength" of the cultural core of the organization. Extremes of either environmental turbulence or stability inhibit organizational learning. Between extreme turbulence and stability, organizations seem to experience a functional tension that promotes learning. Overly-centralized, formalized structures reinforce past patterns of behavior, while organizations that arc more organic allow the action shifts and experimentation that has learning potential. The third dimension, organizational strategies, promotes organizational learning in at least two ways. First, strategy implies a future-orientation and this, combined with goal-setting activities, creates a momentum and a rationale for learning. Second, strategies provide the context within which members perceive and interpret events in their environment.

Organization-wide beliefs, values, and assumptions underpin visible artifacts and patterned behavior and provide symbolic meaning. Thus, culture significantly affects organizational learning. At an extreme, there are "strong cultures," which have a relatively small, exceptionally clear and consistent set of core beliefs and values (Peters \& Waterman, 1982). These cultures may, however, eventually become dysfunctional in that they contribute to reduced learning capacities through their rigidity. The other extreme-no discernible core culture-is likewise dysfunctional since there is no repository for learning. The organization's cultural core also strongly influences perceptions and judgments of strategy, structure, and the environment, thus encouraging or restricting learning. 
Clearly, learning is not passive absorption of information but rather, as Berg- erin (1967) notes, is an active process of translating new knowledge, insights, skills, and values into ones' framework for conduct. Few would argue against the notion that learning and change are inextricably linked within the context of one individual. But what about an organization?

For our purposes, we define organizational learning as the development of organizational insights into, knowledge of, and associations between past actions, the effectiveness of those actions, and future actions (Fiol \& Lyles, 1985). In other words, organizations which have learned behave differently than they did before. While there is some diversity in both the what and the how of organizational learning, there is important agreement as well: (1) that organizational learning is more than the sum of members' learning, (2) that environmental alignment is vital, and (3) that the probability of learning is affected by the degree of environmental turbulence, the rigidity of organizational structure, the adequacy of the organization's strategy, and the strength of its culture.

\section{Organizational Levels of Meaning}

Several scholars of organizational culture have identified levels of meaning as a useful frame of analysis (E. Schein, 1985; Dyer, 1985; Lundberg, 1989). Here, organizations may be viewed as having three levels of meaning: a cultural core, a set of strategic beliefs, and a set of shared cognitive associations. At the center of any organization is the configuration of values and assumptions which constitute its essential character or culture (E. Schein, 1985). This cultural core serves as the foundation upon which the vast majority of thought and action in the organization is based. Values are the collective sense of what should be strived for, the real ideals and standards and sins of the organization. Assumptions are the shared premises on which the organization's top management/dominant coalition bases its world views. Assumptions, therefore, refer to very basic things: the nature of human relationships, the nature of truth and time, the nature of human activity and what classes of people should be given preferential treatment. A central assumption and value always has to do with change.

A second, middle level of meaning, is comprised of strategic beliefs. Strategic beliefs refer to the fundamental "oughts" in the minds of the influential leaders, not the pronouncements of organizational spokes persons. Following Lorsch (1985), four major sets of strategic beliefs are: (a) those of strategic vision-what the organization can become and do and what it won't attempt; (b) those about capital-market expectationsconvictions of what is necessary to keep lenders and investors satisfied; (c) those about product-market competition-understandings of how and why the organization can succeed in its industry and domain; and (d) those about internal managing-the appropriate approaches for operating the organization that support the other beliefs. Strategic beliefs thus cover a wide range of topics and activities, from what financial goals should be to preferred technologies, from the best set of employee inducements to 
acceptable union-management relationships, from what are acceptable risks to what are appropriate relationships, and soon.

Strategic beliefs reflect the cultural core as they, in turn, strongly influence the most surface level of meaning. We call this level of meaning cognitive association, for it is comprised of patterns of action-outcome relationships; that is, the mental connection that action $\mathrm{X}$ will result in outcome $\mathrm{Y}$. These relationships may be conscious or unconscious, based on empirical evidence or simply imagined. Regardless, they are the basis of employees' perceptions of their experiences and their subsequent interpretations and response. As a set, these cognitive associations predispose members to experience organizational activities and events in certain ways, to identify similar problems and issues, to engage in performance within certain agreed upon limits, and to strive toward common goals. Over time, organizational members come to share, more or less completely, a common set of action-outcome associations-what is usually understood as organizational "know-how," what Argyns (1982) calls an organization’s "theory in use," but which we will call its "operational cause-map" (Lundberg, 1989; Kuhn, 1962).

\section{Organizational Learning and Performance}

With these three organizational levels of meaning distinguished, both normal organizational performance and organizational learning may now be easily described. Keep in mind that organizations are purposive, that organizational purpose is defined in terms of specific outcomes, and that, ultimately, outcomes are the products of a set of action-outcome relationships believed and performed by members. Normal organizational performance occurs in the following cycle. Initially, members attend to things, activities, and events in terms of that portion of the operational cause-map understood by them. Then, as familiar performance gaps are noticed (the difference between goals and standards and observed performance), problems are identified. Previously learned action (consistent with relevant action-outcome relationships) is then undertaken, and the results of successful actions reinforce action-outcome relationships (Weick, 1979).

Let us look at a couple of examples; one about individual performance, another about organizational performance. A supervisor of a typing pool routinely examines a sample of the envelopes awaiting mailing (attending). When she notices an address without the zip code (performance gap), she asks the typist to be more careful (previously learned action). The typist subsequently includes zip codes (reinforcing the supervisor's behavior). At the organizational level, consider the events following top management's comparison of quarterly profit and loss statements with the financial goals for the period (attending). Revenue shortfalls (performance gaps) prompt instructions to the sales, credit, and cost control managers (previously learned actions). If the actions of these departments correct the revenue shortfall, these actions will be repeated the next time a 
similar problem occurs (reinforcement). If the actions do not correct the shortfall, top management will identify and subsequently implement other actions.

Turning now to organizational learning, we describe three separate but parallel learning cycles. Each of these cycles corresponds to one of the fundamental organizational tasks noted previously; adjustment, adaptation, and anticipation.

\section{Organizational Learning Cycles}

Adjustment-focused organizational learning, the first type, begins with the recognition of a novel problem. By definition, this requires actions that are not in the repertoire of the set of action-outcome associations, the collective organizational "knowhow" or what we call the operational cause-map. Search behavior is then required. $\mathrm{N}^{\wedge} \mathrm{W}$ tactical actions are selected, and experimental actions initiated. Actions that appear successful are then retained and are added to or alter the existing cognitive associations in the operational cause-map. Over time, when major problems or a succession of more minor, novel problems have been successfully dealt with, the operational cause-map of the organization's members may substantially change. Even with partial modifications, however, we can say the organization has "learned," for a set of its members will substantially perceive and interpret their experiences differently from that point on.

The second type of organizational learning, adaptation, begins with the recognition that important issues involving organization-environment relationships are being experienced, and this both bothers and puzzles key members. Examples of common puzzles are market strategies that are not working or unexplained shifts in the availability of critical resources. When the perceived state persists, organizational members eventually acknowledge that some new strategic organizational action is required. There is a search for an appropriate strategy and, if the search is unsuccessful, new strategies are invented. When new strategies are implemented through tactical actions-"how to do its"-and found effective for resolving the alignment puzzle, two sorts of learning consequences occur. First, as with novel problem solving, the tactical actions called for by the new strategy redefine prior action-outcome relationships and there is modification of the operational cause- map. In addition, the premises of the successful strategy are incorporated into the organization's set of strategic beliefs. Thus, with the conclusion of this cycle, organizational learning has occurred in two parallel ways.

Anticipative organizational learning, the third type, begins with a recognition that the way the organization understands itself is no longer sufficient. This comes about when members realize that the future strategic actions being contemplated will probably not suffice. This is an anomaly and, when judged significant, it is experienced as a predicament. Major, anticipatory changes seem called for-nothing less, in effect, than a reformulation or transformation of the organization's culture. The anticipative learning cycle, once initiated, goes forward as follows. Systematic futurizing is practiced, and the results are compared to the organization's present culture and members' strategic beliefs. 
The gap discovered is first filled by a vision of a more appropriate organization in the probable future. Then, a transition strategy is selected (Lundberg, 1984; Beckhard \& Harris, 1987). Implementation of this transition plan usually necessitates a number of things, such as a reformulated organizational mission, new long-range plans, the redesign of organization structures, systems, policies, and any number of tactical interventions. The magnitude and number of things changed means that elements of the cultural core are altered, strategic beliefs modified, and the operational cause-map changed —a rare but truly transformational learning process.

These three types of organizational learning, summarized in Table 1, may be understood as occurring at different levels in a hierarchy of learning levels. Adjustment learning, as noted, involves rearranging and redesigning the components of organizations, what Bateson (1972) terms first-order changes. Adaptive and anticipatory cycles of organizational learning are at a higher level. They are second-order changes, a form of meta-learning that requires rethinking the patterns that connect the pieces of the organization and relate them to the environment (Levy, 1986). The scope of second-order change may be comparatively narrow or comparatively wide (Bartunek \& Louis, 1988), from introducing participative supervision to refocusing the organization's mission. This higher level, what Aigyris and Schon (1978) call double-loop learning, reframes organizational dynamics. Lower-level learnings, by contrast, are aimed at particular behavioral performances and their cognitive associations. This is the level at which much of the work in organizational communication has been focused. Higher level learning seeks to develop new interpretive bases, and it is at these extended levels of concern that organizational learning may make its most significant contribution in extending the boundaries of organizational communication.

If we use the lens provided by organizational learning, we can appreciate the familiar as well as discover previously unseen aspects of organizational communication. The arena of organizational communication is thereby both deepened and broadened to include not only individual performance but also the higher level issues of environmental/organizational adaptation and anticipatory organizational transformation.

\section{Toward a "Meaning-Full" Model of Organizational Communication}

Organizational learning appears to offer significant insights into organizational communication. As we have seen, organizational learning focuses on meaning creation and modification at several levels. It is essentially a dynamic change process that enlarges the domain of organizational communication. We now propose a model that facilitates analysis both within and across individual and organizational levels as well as first and second level orders of change. This model considers both content and process while keeping the concept of meaning central.

Our discussion builds through three stages. First, we redefine the scope of organizational communication and carefully explicate its meaning. The components of 
our definition become the conceptual base for extending the basic communication event to include all three levels of the organizational learning processes. Finally, we attempt to show how this model redefines both maintenance- and change-related organizational behavior.

\section{Expanding the Boundaries of Organizational Communication}

We propose the following definition of organizational communication: the patterned process of sharing meaningful information among the social entities of an organization. This unusual definition immediately begs that its three key terms be clarified: what do we mean by "social entities," "meaningful information," and "patterned process of sharing"?

Social Entities. Traditionally, organizational communication refers to the processes and structures of communication between persons or positions (Redding and Tompkins, 1988). This conventional definition of communication senders and receivers, we contend, limits our view of this multi-dimensional process. The "social entity" in our definition refers to what we will call a role. We define role as a patterned set of behaviors or activities exhibited by a person. Here, roles are not synonymous with either formal or social positions; rather, we conceive of position incumbents as typically performing many different roles. Role is a patterned set of behaviors or activities that is reasonably consistent over time. Managers, for example, have been observed to perform at least ten roles (Mintzberg, 1973): figurehead, leader, liaison, monitor, disseminator, spokesperson, negotiator, resource allocator, disturbance handler, and entrepreneur.

Our choice of role for both communication sender and receiver enables us to conceive of communication within and between all of the conventional social science units of analysis. All levels, from intrapersonal communication to those communications between communities or societies, can be accommodated within this framework. Thus, roles are the entities through which persons talk with themselves, with other persons, or act as spokes persons for groups, organizations, or larger social units. Observing two employees talking with one another in an office setting, for example, tells us nothing until we understand their roles. Are these two friends talking as individuals? A bowling team spokesperson talking to a potential recruit? The representatives of two cliques talking on a committee? The office manager talking to an employee? Management and union representatives talking? Figure 1 illustrates the numerous combinations of communication participants with role always understood to be the social entity sending and receiving messages.

With reference to Figure 1, each cell specifies communication phenomena between the conventional levels of social analysis as well as within a particular unit. Always, however, the role is the operative sender or receiver. For example, intrapersonal communication is now defined as two or more roles communicating" with each other, such as one's spouse role to one's employee role. Intragroup communication between 
member roles may be understood as between task and maintenance roles, leader and follower roles, etc.

Intraorganizational communication is likewise defined as two members of the same organization communicating in terms of specific roles. A problem-identifier may communicate with a source of technical information, or a decision-maker may seek advice from his or her mentor. Interpersonal communication (cell 1) is now defined as two individuals communicating via one of any number of very specific roles. Intergroup communication (cell 6) has members of two different groups communicating via their group roles, e.g., the task leader of group A and the socioemotional leader of Group B. Inter-organizational communication (cell 13) occurs between the roles performed by members of two or more organizations. Negotiators, for example, may represent a company, a union, and the facilitator assigned by the Federal Mediation Service. We can see how the choice of role enables consideration of all possible types of communication events that could occur within and about organizations.

Meaningful Information. Given role as the social entity, what is "meaningful information"? Meaning resides in the relationship among two or more cognitive elements. All knowledge is thus composed of statements of two or more ideas that arc linked either by association or causality (Figure 2). Statements of association (I-I) specify that two or more ideas (and what they stand for) are found together with some probability. Statements of causality (A-O) specify that two or more ideas (and what they stand for) have an action-outcome probability. Both types of statements, of course, vary from simple (just two ideas) to complex (multiple Is, As, and Os). In addition, we note that ideas vary in terms of their scope or degree of abstractness, their clarity or precision, and whether they are unique to a person or shared among a set of people. We further note that ideas and their relationships may be empirically verifiable or simply imagined.

Statements, our vehicles for communicating meaningful information, occur on two levels also. Level one is composed of statements that describe some portion of the world as we believe or know it; these are statements about content. Level two is composed of statements that tell us how we should apply the statements of level one. Level two statements can be seen as rules for conduct, and may be either prescriptive or proscriptive. Meaningful information thus can be classified by combining the two forms of statements (associative and causative), and the two levels (content and rules for conduct) as shown in Figure 2. Let us illustrate these four types. At the content level, level one, an I-I statement is: The more unfamiliar ideas per page, the more likely the reader will be confused. At level one, an A-O statement is: The repetition of unfamiliar ideas increases reader comprehension. Turning to level two, rules for conduct, an I-I statement is: To reduce confusion, space out unfamiliar ideas with examples. An A-O illustration at level two is: To increase comprehension of unfamiliar ideas, repeat them.

Each of the four types of meaningful information can also be conceived in terms of time. Three aspects of time appear to be pertinent. One is the past until the present 
moment. Here, associative and causal statements at both levels are known as experience or as history. A second aspect of time is the future. In the future, meaningful information is speculative. Forecasts are examples of level one statements and strategic beliefs are examples of level two statements. The third aspect of time is timelessness; meaningful information here ostensibly is not time-bound. Physical laws and social values are examples of timeless statements. Meaningful information, in our definition of organizational communication, is now understood as time-indexed, associative and causal probability statements of content and rules for conduct.

Patterned Process of Sharing. Up to this point we have shown that organizational communication involves meaningful information and roles, but we have not yet spoken to the "patterned process of sharing" this information among roles. It is to this we now turn. In short, the transfer of meaningful information between roles implies a direction, a sending and receiving function. Thus, the process of sharing in its simplest terms means that a person performing one role produces (either intentionally or unintentionally) information that is perceived by another person performing a role. These roles can represent a variety of social units of analysis (recall Figure 1). As discussed earlier, role enactors who are related to an organization learn to expect certain communication from others. Thus, role behavior is understood to be repetitive. It is this repetition of information transfer between roles that constitutes what we mean by patterned sharing.

\section{A Role-Based Model of Organizational Communication}

Our discussion to this point invites us to reconsider the basic communication event presumed to be common to all organizational communication phenomena. Traditionally, this event has a message sent from a sender to a receiver. We now understand that senders/receivers are neither persons or positions, but roles. These roles are patterned sets of behaviors and activities which represent individuals, groups, organizational sub-units, organizations, and larger social systems. Further, messages are understood to be perceived as meaningful information, either associative and causative statements of content or rules for conduct. The traditional communication event,

Of course, this diagram drastically oversimplifies the possibilities of organizational communication. On the one hand, we have already noted that meaningful information may take the form of content or rules for conduct. On the other hand, we have also noted that sender/receiver roles may reflect either the formal or informal social systems at several levels of analysis. These points, taken together, provide a description of the possibilities for the basic communication process event we posit (those associated with the person him or herself, those associated with the informal social system, and those associated with the formal organization), a focal receiving role (representing either an individual role, a role of the informal social system, or a role of the formal organization), and two types of meaningful information. Figure 3 shows the elements of a 
basic organizational communication model. Although positioned centrally within the symbolic-cultural tradition, it also incorporates aspects of what has become known as the "rules perspective" on organizational communication (Cushion, King, \& Smith, 1988).

Of particular interest are the statements of meaningful information termed causal probability, the action-outcome relationships (A-Os) referred to earlier. Recall that these occur at two levels; the level of content (level one) and the level of rules for conduct (level two). Given our specification of three kinds of sending roles, we are able to identify a typology of A-Os, as noted in Figure 4.

The communication model portrayed in Figure 3 suggests the characteristics of both effective and ineffective organizational communication. Effective communication, we hypothesize, will be characterized by A-0 statements that are clear and complete, relatively consistent, and which are perceived as coming from a legitimate role sender. AOs (from whatever source) which are incomplete or unclear result in message ambiguity. Inconsistent A-Os stemming from one or more salient others result in conflict. A-Os perceived as stemming from non-legitimate senders are either distorted or edited out. Communication overload is now understood to be role overload. Subsequent role behavior is often appraised by the original role sender. When his or her A-0 is compared to the receiver's behavior and a discrepancy noted, it may stimulate either a repetition of the original A-0 or a shift to another level.

We now examine how this model contributes to our understanding of larger organizational processes. Behavior in organizations requires coordination so that members' efforts contribute to the achievement of larger goals. As we know, however, organizations seldom exist in a totally stable environment. The three fundamental organizational tasks (management of internal operations, alignment with the environment, and anticipation of changing contexts) reflect the need for both ongoing coordination and responsiveness to changing environments. Organizational communication becomes the major vehicle for all of these vital pro- 065565-for ongoing coordination and maintenance, and for organizational change. We now show how our role and meaning-centered reconceptualization of organizational communication may account for both maintenance and change.

\section{Organizational Maintenance and Change}

Organizational members' goal-directed performances under relatively nonchanging circumstances (organizational maintenance) are actually very dynamic, as organizational learning theory has already indicated. From the perspective of our communication model, then, how does organizational performance occur? Whether work is being initiated, performed, or terminated, all organizational members utilize the same cyclic process. Below we describe this performance cycle for an individual member, noting that it is applicable to sets of members and hence to all types of communication for all human organizational systems. 
The performance cycle begins with an individual, in a role, who attends to some things, behaviors, or events. Organizational members, in other words, perceive something through the lens provided by the sets of relevant statements they hold. Members will vary in the degree to which they hold common sets of meaningful information (previously referred to as an operational cause-map). New members, members of very new organizations, and members of organizations with a weak culture tend to hold more individually dispersed sets of meaningful information. Members with some degree of seniority or centrality to an organization (especially managerial members), however, usually share the operational cause- map to a large extent. Regardless, some things, behaviors or events, are seen as performance gaps; that is, what is perceived is incongruent with expectations, goals, or standards. This performance gap, or "problem," triggers corrective action. The action initiated is, of course, consistent with previously acquired A-0 statements. When the action has occurred, it is appraised for its effectiveness. When judged effective, it reinforces the previously held and utilized A-Os. If the action isn't effective, an alternative A- 0 is tapped and enacted until effectiveness is achieved.

This cycle of normal performance is shown in Figure 5. Each stage of this cycle is a communication event, whether it is describing individual behavior as simple as turning on a machine, approaching a customer, or reviewing an annual budget. The cycle also describes more complex human activities such as conducting a performance appraisal, holding a board meeting, or conducting marketing research. Let us also emphasize that when two or more members are involved, and when more than simple activities or events are being considered, they can be described with multiple, interconnected performance cycles. You may note a resemblance between this cycle described and the natural selection process adapted to social behavior (socio-cultural evolution model) by Campbell (1970) and applied to organizations by Weick (1979).

Three levels of organizational meaning have just been outlined. The point has been made that when the operational cause-map, the set of strategic beliefs, or the core configuration of assumptions and values is altered, the organization could be said to have learned because, thereafter, member activities would be different than they were before. Clearly, organizational learning implies change. How do such changes occur? How does organizational communication contribute to change?

Organizational change, like organizational maintenance, is also a dynamic, cyclic process. For clarity, we again describe this change cycle in terms of one organizational member. As before, however, the change cycle actually applies to multiple-member, large-change tasks, too. The change cycle, like all organizational behavior, is a rolefocused sequence of communication events. A member, in a particular role, holding some portion of the operational cause-map, attends to activities, events, or behaviors.

Occasionally, discrepancies are noted which are not familiar performance-gaps; they are novel or are generally puzzling. With this interpretation, the search for relevant A-Os 
begins. The more these discrepancies are understood to be organizationally significant (concern environmental adaptation in the near or far future), and the more unfamiliar they arc, the more likely it is that relevant A-Os will be general in nature. If search does not turn up reasonable A-Os as premises for action, new A-Os will have to be invented. General A-Os with strategic implications are then used to create more specific A-Os (guides to tactical actions).

New product lines, for example, will require new marketing plans which, in turn, must be translated into a myriad of sub-activities from packaging to promotion. The appropriate experimental actions are then implemented. Some time thereafter, the set of actions is assessed. When judged effective, some subset of both the operational causemaps, its A-Os, and the set of strategic beliefs/core configuration of values and assumptions, are either altered or replaced. Figure 6 diagrams this cycle of change. We note again that each stage of the cycle described outlines the need for one or more (typically many more) applications of our basic organizational communication model.

\section{Concluding Commentary}

Initially, we examined the field of organizational communication with an eye to the insights provided by the symbolic/cultural perspective. We discovered a field of vigor but one in which surprisingly little attention has been given to macro phenomena (how organizations relate to their external environments, the process of organizational change, etc.).

We then introduced the emerging field of organizational learning which explicitly deals with the macro phenomena that organizational communication has yet to fully explore. Our intent was to let organizational learning provide guidance for reconceptualizing organizational communication. The discussion of organizational learning brought to our attention: (1) the organization's fundamental tasks, (2) the various levels of meaning, (3) contextual and other organizational level factors, and (4) the dynamics of how organizations operate to make internal adjustments, adapt to their environments, and anticipate their probable futures.

In the third section of our essay we offered our organizational learning-influenced model of organizational communication. This required a redefinition of organizational communication as a patterned process of sharing meaningful information among social units at all levels of analysis. The model of organizational communication that emerged emphasized how meanings are generated, stored, and shared; that is, how content is governed by rules of conduct. The model was then used to examine the interpersonal communications which are the traditional focus of the organizational communication field. It was also applied to illustrate how organizations accomplish their normal activities and how the change process occurs.

The relevance of our model to organizational communication can be assessed in at least two ways: first, according to its utility for understanding and guiding organizational 
behavior (pragmatic relevance) and second, its utility for contributing to our knowledge of organizational communications (theoretical relevance).

\section{Pragmatic Relevance}

The model's focus on role as the social entity for sending and receiving messages has important implications for practitioners. What role or roles are operative in communication events? This question, if persistently asked and answered, would surely enhance our understanding of organizational communication. Awareness of what social units were represented by sending/receiving roles would eliminate confusion as to message legitimacy and importance. Such an awareness might prompt communicators to cue their role intentions, too, thus contributing to the effectiveness of both senders and receivers. At a minimum, communication role awareness should permit members responsible for various organizational units (teams, departments, etc.) to appraise the appropriateness of intra- and inter-unit communications.

Meaningful information, as defined and differentiated in the model, also has pragmatic importance. An awareness of content aspects (as distinguished from rules of conduct aspects) should enable communicators to unravel messages more accurately as well as to interpret communication intentions more precisely. Roles and meaningful information together provide a way of understanding what constitutes effective and ineffective communication. Clarity and ambiguity, what is legitimate and non-legitimate, consistent or conflicting - as well as other features of organizational communicationare now more easily deciphered.

These aspects of our model should enhance understanding of communicative events in all mediums and channels because of the increased precision of analysis allowed. Interestingly, much of our present prescriptions for enhancing organizational communication-from active listening to message redundancy, from conference leadership to the use of electronic mail, from time management to agenda arrangements, from supervisor training to public relations — take on new meaning when interpreted through the lens provided by our model. All such practices become sharpened when roles and meaningful information are taken into account.

In general, then, our model provides the practitioner with a meta-language that can be used to analyze the substance and processes of both everyday exchanges as well as over-arching organizational conditions. The enhanced awareness of the choices and constraints influencing communication encounters that this model engenders should lead to improved practices and the discovery of new devices as well.

\section{Theoretical Relevance}

The relevance of our reconceptualized model of organizational communication to communication theory is multi-faceted. Many of the ideas currently central to communication theory (e.g., assumptions, norms, and values), which are themselves often 
ambiguous, can now be more carefully examined. Our conception of messages as identified on two dimensions, I-I or A-O, and as either content or rules for conduct, provides the means for redefining the sorts of ideas just noted. Theoretically, our model also contributes to the symbolic/cultural approach in that it argues for the centrality of meanings in all organizational communications by demonstrating how meanings are formed and shared and how they affect organizational behavior, performance, and change.

The symbolic/cultural approach has suffered from the fact that many of its ideas are known only through inference. Our model suggests how these ideas may be grounded in observations of concrete performances. Beyond providing a new dimension to the symbolic/cultural approach, our model also utilizes a rules approach. Although much has been written regarding rules approaches to the study of symbolic interactions, it too has suffered from an inadequate grounding of the phenomena. Our model moves toward phenomenonological grounding by suggesting that messages themselves are rule-laden, and that these rules of conduct can be analyzed on two levels. Further, we have shown how the symbolic/cultural and rules approaches may be integrated. Perhaps of most theoretical significance, however, is the fact that this model may have the potential for integrating other approaches as well, reducing the theoretical fragmentation of the field.

For all of the implied or asserted promise of this model, both pragmatically and theoretically, much remains to be done. While it appears to offer considerable potential, the ideas presented here no doubt require further clarification. After these ideas are clarified, they must be operationalized. Only then can our present knowledge of organizational communication be translated into the rules that might serve to guide communicative behaviors in organizations. Only then can research be designed to discover empirically significant distributions, associations, and effects. Only then can further theoretical elaboration and integration be undertaken. 


\section{References}

Argyris C. (1970). Intervention theory and method: A behavioral science view. Reading, MA: Addison-Wesley.

Argyris, C. (1982). Reasoning, learning and action. San Francisco: Jossey-Bass.

Argyris, C., \& Schon, D. (1978). Organization learning. Reading, MA: Addison-Wesley. Barnett, G. A. (1988). Communication and organizational culture. In G. M. Goldhaber \& G. A. Barnett (Eds.), Handbook of organizational communication (pp. 101-130). Norwood, NJ: Ablex.

Bartunek, J. M. (1984). Changing interpretative schemes and organizational restructuring: The example of a religious order. Administrative Science Quarterly, 29, 355-372.

Bartunek, J. M., \& Louis, M. R. (1988). The interplay of organizational development and organizational transformation. In R. Woodman \& W. Pasmore (Eds.), Research in organizational change and development (Vol. 2, pp. 97-134). Greenwich, CT: JAI Press.

Bateson, G. (1972). Steps to an ecology of the mind New York: Ballatine.

Beckhard, R. (1969). Organization development: Strategies and models. Reading, MA: Addison-Wesley.

Beckhard, R., \& Harris, R. T. (1987). Organizational transitions (2nd ed.). Reading, MA: Addison-Wesley.

Bergerin, P. (1967). A philosophy of adult education. New York: Seabury.

Bolman, L., \& Deal, T. (1984). Modem approaches to understanding and managing organizations. San Francisco: Jossey-Bass.

Campbell, D. T. (1970). Natural selection as an epistemological model. In R. Naroll \& R. Cohen (Eds.), Handbook of methods in cultural anthropology (pp. 51-85). Garden City, NJ: Natural History.

Chakravarthy, B. S. (1982). Adaptation: A promising metaphor for strategic management. Academy of Management Review, 7, 735-744.

Chandler, A. (1962). Strategy and structure. Cambridge, MA: MIT Press.

Cushion, D. P., King, S. S., \& Smith, T. (1988). The rules perspective on organizational communication research. In G. M. Goldhaber \& C. A. Barnett (Eds.), Handbook of organizational communication (pp. 55-94). Norwood, NJ: Ablex.

Cyert, R. M., \& March, J. G. (1963). A behavioral theory of the firm. Englewood Cliffs, NJ: Prentice-Hall.

Dansereau, F., \& Markham, S. E. (1987). Superior-subordinate communication: Multiple levels of analysis. In F. M. Jablin, L. L. Putnam, K. H. Roberts \& L. W. Porter (Eds.), Handbook of organizational communication (pp. 75-91). Newbury Park, CA: Sage.

Deal, T., \& Kennedy, A. (1982). Corporate culture: The rites and rituals of corporate life. Reading, MA: Addison-Wesley. 
Duncan, R. D. (1974). Modifications in decision structure in adapting to the environment: Some implications for organizational behavior. Decision Sciences. 5. 705-725.

Dutton, J., \& Duncan, R. (1983). The creation of momentum for change through the process of organizational sense-making. Unpublished manuscript, Graduate School of Business Administration, New York University, New York City.

Dyer, G. Jr. (1985). The cycle of cultural evolution in organizations. In R. H. Kilmann, N. J. Saxton \& R. Serpa (Eds.), Gaining control of the corporate culture (pp. 200229). San Francisco: Jossey-Bass.

Eisenberg, E. M., \& Riley, P. (1988). Organizational symbols and sense-making. In G. M. Goldhaber \& G. A. Barnett (Eds.), Handbook of organizational communication (pp. 131-150). Norwood, NJ: Ablex.

Fiol, C. M., \& Lyles, M. A. (1985). Organization learning. Academy of Management Review, 10, 803-813.

Goldhaber, G. (1983). Organization communication (3rd ed.). Dubuque, IA: William C. Brown.

Hedberg, B. (1981). How organizations learn and unlearn. In P. C. Nystrom \& W. H. Starbuck (Eds.), Handbook of organizational design (pp. 3-27). London: Oxford University Press.

Huseman, R. C., Hayes, M. A., \& Alexander, E. R. III (1977). Communicating organizational change: A case study. In R. C. Huseman, C. M. Logue \& D. L. Freshley (Eds.), Readings in interpersonal and organizational communication (3rd ed., pp. 377-392). Boston: Holbrook.

Jackson, C. N. (1985). Training's role in the process of planned change. Training and Development Journal, 39 (2), 71.

Jelinek, M. (1979). Institutionalizing institutions: A study of organizational learning systems. New York: Praeger.

Katz, D., \& Kahn, R. (1966). The social psychology of organizations. New York: Wiley.

Kuhn, T. S. (1962). The structures of scientific revolutions. Chicago: University of Chicago Press.

Lawrence, P., \& Lorsch, J. (1967). Organizations and environment. Boston: Harvard Business School.

Levitt, B., \& March, J. G. (1988). Organizational learning. Annual Review of Sociology. 14, 319-340.

Levy, A. (1986). Second order planned change: Definition and conceptualization. Organizational Dynamics. 15, 5-20.

Likert, R. (1961). New patterns of management. New York: McGraw-Hill.

Lorsch, J. W. (1985). Strategic myopia: Culture as an invisible barrier to change. In R. H. Kilmann, M. J. Saxton \& R. Serpa (Eds.), Gaining control of the corporate culture (pp. 84-102). San Francisco: Jossey-Bass. 
Lundberg, C. (1984). Strategies for organizational transitioning. In J. R. Kimberly \& R. E. Quinn (Eds.), Managing organizational transitions (pp. 60-82). Homewood, IL: Irwin.

Lundberg, C. (1989). On organizational learning: Implications and opportunities for expanding organizational development. In R. Woodman \& W. Passmore (Eds.), Research in organization change and development (Vol. 3, pp. 61-82). Greenwich, CT: JAI Press.

McGregor, D. (1960). Human side of enterprise. New York: McGraw-Hill.

Meyer, A. (1982). Adapting to environmental jolts. Administrative Science Quarterly. 27, 515-537.

Miles, R. H. (1982). Coffin nails and corporate strategies. Englewood Cliffs, NJ: Prentice- Hall.

Miles, R. H., \& Snow, C. C. (1978). Organizational strategy, structure and process. New York: McGraw-Hill.

Mintzberg, H. (1973). The nature of managerial work. New York: Harper \& Row.

Mintzberg, H., \& Waters, J. (1982). Tracking strategy in an entrepreneurial firm. Academy of Management Journal. 25, 465-499.

Pacanowsky, M., \& O'Connell-Trujillo, N. (1982). Communication and organizational cultures. New York: McGraw-Hill.

Peters, T., \& Waterman, R. H. (1982). In search of excellence. New York: Harper \& Row.

Pettigrew, A. M. (1975). Towards a political theory of organizational intervention. Human Relations. 28 (3), 191-208.

Putnam, L. L., \& Pacanowsky, M. (1983). Communication and organizations: An interpretative approach. Beverly Hills, CA: Stage.

Putnam, L. L., \& Poole, M. S. (1987). Conflict and negotiation. In F. M. Jablin, L. L. Putnam, K. H. Roberts \& L. W. Porter (Eds.), Handbook of organizational communication (pp. 107-121). Newbury Park, CA: Sage.

Rapaport, A. (1970). Modern systems theory: An outlook for coping with change. General Systems, 15, 15-26.

Redding, W. C., \& Tompkins, P. K. (1988). Organizational communication: Past and present tenses. In G. M. Goldhaber \& G. A. Barnett (Eds.), Handbook of organizational communication (pp. 5-34). Norwood, NJ: Ablex.

Roberts, K. H., \& O'Reilly, C. A. Ill (1978). Organizations as communication structures: An empirical approach. Human Communication Research, 4, 283-293.

Schein, E. (1985). Organizational culture and leadership. San Francisco: Jossey-Bass.

Schein, V. E. (1985). Organizational realities: The politics of change. Training and Development Journal, 39, 37-41.

Schein, V. E. (1977). Political strategies for implementing organizational change. Group \& Organization Studies, 2, 42-48. 
Shrivastava, P. (1981). Strategic decision making process: The influence of organizational learning and experience. Unpublished doctoral dissertation, University of Pittsburgh.

Shrivastava, P., \& Mitroff, I. I. (1983). Frames of reference managers use: A study in applied sociology of knowledge. In R. Lamb (Ed.), Advances in strategic management (Vol. 1, pp. 161-182). Greenwich, CT: JAI.

Simon, A. (1969). Sciences of the artificial. Cambridge, MA: MIT Press.

Smircich, L. (1983). Concepts of culture and organizational analysis. Administrative Science Quarterly, 28, 257-273.

Starbuck, W. H., Greve, A., \& Hedberg, B. (1978). Responding to crises. Journal of Business Administration, 9,112-137.

Susman, G. I., \& Evered, R. D. (1978). An assessment of the scientific merits of action research. Administrative Science Quarterly, 23, 582-603.

Thayer, L. (1968). Communication and communication systems. Homewood, IL: Irwin.

Weber, M. (1947). The theory of social and economic organizations. Translated by A. M. Henderson \& T. Parsons, and edited by T. Parsons. New York: Oxford University Press. [Originally published 1929]

Weick, K. E. (1979). The social psychology of organizing. Reading, MA: AddisonWesley.

Wigand, R. T. (1979). Some recent developments in organizational communication: Network analysis-A systemic representation of communication relationships. Communications: International Journal of Communication Research, 2, 181-200. 
Table 1. Fundamental Organizational Tasks

\begin{tabular}{|c|c|c|c|c|}
\hline $\begin{array}{l}\text { Fundamental } \\
\text { Organizational } \\
\text { Task }\end{array}$ & $\begin{array}{l}\text { Initiating } \\
\text { Stimuli }\end{array}$ & $\begin{array}{l}\text { Organizational } \\
\text { Learning } \\
\text { Focus }\end{array}$ & $\begin{array}{l}\text { Primary } \\
\text { Leaming } \\
\text { Mechanism }\end{array}$ & $\begin{array}{l}\text { Leaming } \\
\text { Outcomes }\end{array}$ \\
\hline Adjustment & $\begin{array}{l}\text { Novel } \\
\text { Problem }\end{array}$ & $\begin{array}{l}\text { Operational } \\
\text { Cause-Map }\end{array}$ & $\begin{array}{l}\text { Reformulation of } \\
\text { Action-Outcome } \\
\text { Relationships }\end{array}$ & $\begin{array}{l}\text { More Effective } \\
\text { Management } \\
\text { of Internal } \\
\text { Operations }\end{array}$ \\
\hline Adaptation & Puzzles & $\begin{array}{l}\text { Strategic } \\
\text { Beliefs }\end{array}$ & $\begin{array}{l}\text { Modification of } \\
\text { Strategies \& } \\
\text { Premises }\end{array}$ & $\begin{array}{l}\text { Improved } \\
\text { Organization- } \\
\text { Environment } \\
\text { Alignment }\end{array}$ \\
\hline Anticipation & Predicament & $\begin{array}{l}\text { Core Values \& } \\
\text { Assumptions }\end{array}$ & $\begin{array}{l}\text { New Vision of } \\
\text { the Cultural } \\
\text { Core }\end{array}$ & $\begin{array}{l}\text { Enhanced } \\
\text { Organizational } \\
\text { Sense-Making \& } \\
\text { Anticipation }\end{array}$ \\
\hline
\end{tabular}


1. Individual $\mathbf{A}$

2. Group A

3. Organizational Subunit A

4. Organization A

5. Community/Society A

\begin{tabular}{|c|c|c|c|c|}
\hline 1 & 2 & 3 & 4 & 5 \\
\hline 1 & 2 & 3 & 4 & 5 \\
\hline & 6 & 7 & 8 & 9 \\
\hline & & 10 & 11 & 12 \\
\hline & & & 13 & 14 \\
\hline & & & & 15 \\
\hline
\end{tabular}

Figure 1. A Matrix of Communication Possibilities 


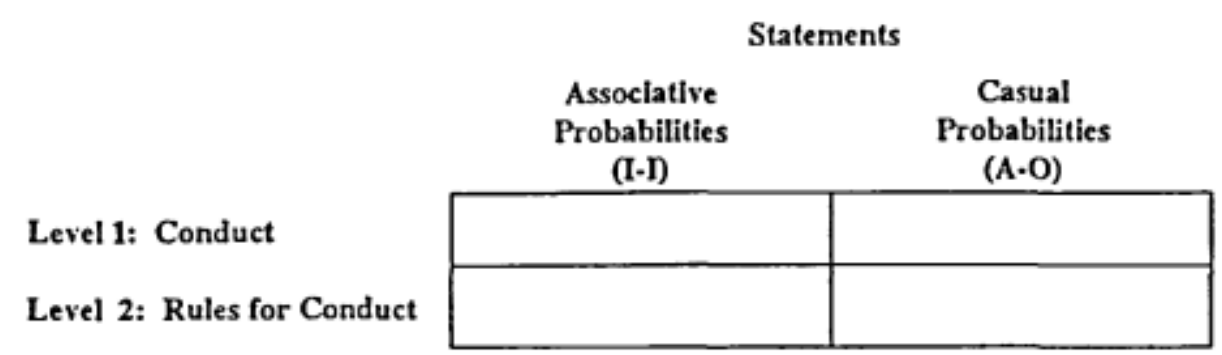

Figure 2. A Classification of Meaningful Information 


\begin{tabular}{|c|c|c|}
\hline $\begin{array}{l}\text { Possible Sources of } \\
\text { Sending/Receiving Roles } \\
\\
\quad \text { (Level 1 }\end{array}$ & $\begin{array}{l}\text { Message } \\
\text { or Level 2; I-I }\end{array}$ & $\begin{array}{l}\text { Possible Sources of } \\
\text { Sending/Receiving Roles }\end{array}$ \\
\hline $\begin{array}{l}\text { Person } \\
\text { Formal } \\
\text { Organization } \\
\text { Informal } \\
\text { Social } \\
\text { System }\end{array}$ & $\begin{array}{c}\text { Perceived } \\
\text { Meaningful } \\
\text { Information }\end{array}$ & $\begin{array}{l}\text { Person } \\
\text { Formal } \\
\text { Organization } \\
\text { Informal } \\
\text { Social } \\
\text { System }\end{array}$ \\
\hline
\end{tabular}

Figure 3. Basic Organizational Communication Model 
Sending Role

Self

Formal Organization

Informal Social System
Level 1:

Content

Level 2:

Rules for Conduct

\begin{tabular}{|c|c|}
\hline Behavioral Injunctions & Personal Values \\
\hline Procedures & Policies/Plans/Strategies \\
\hline Norms/Conventions & Social Beliefs \\
\hline
\end{tabular}

Figure 4. Typology of A-Os 


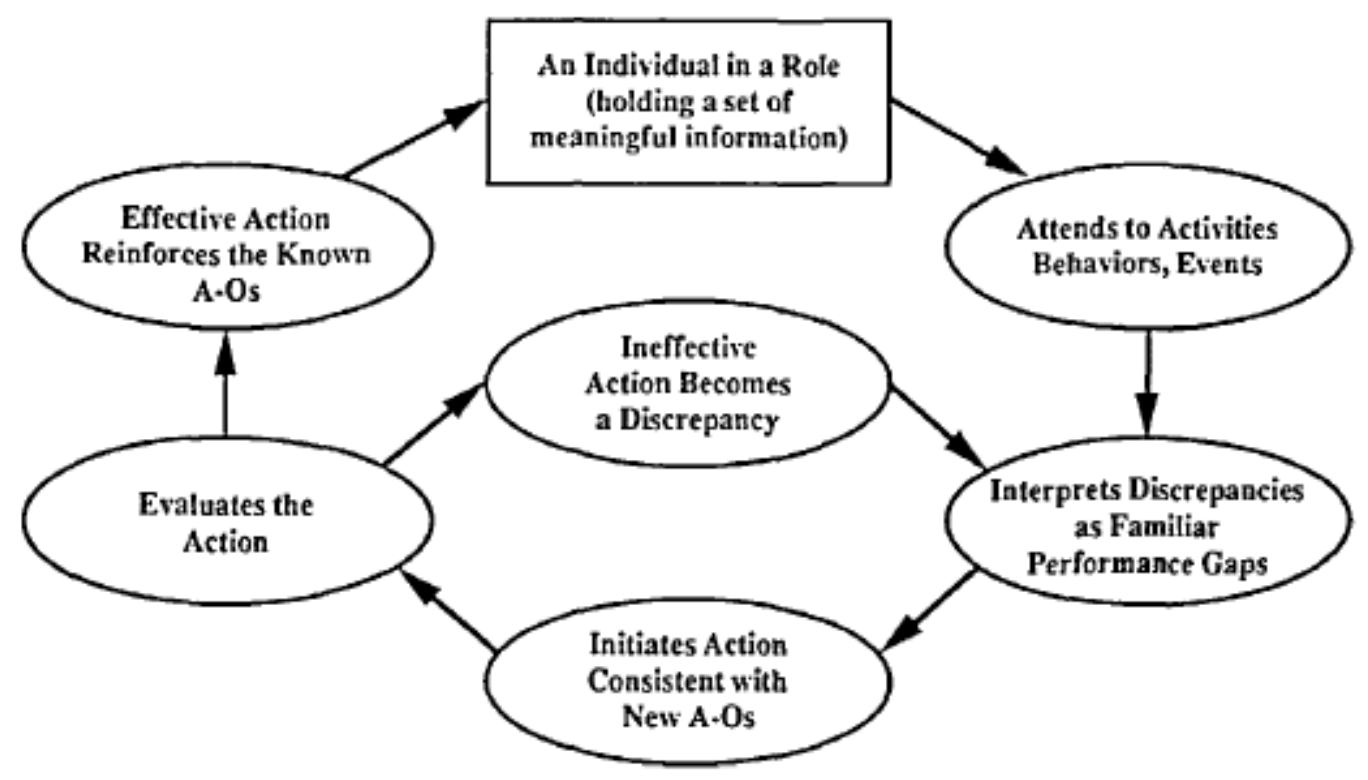

Figure 5.Organizational Performance Cycle 


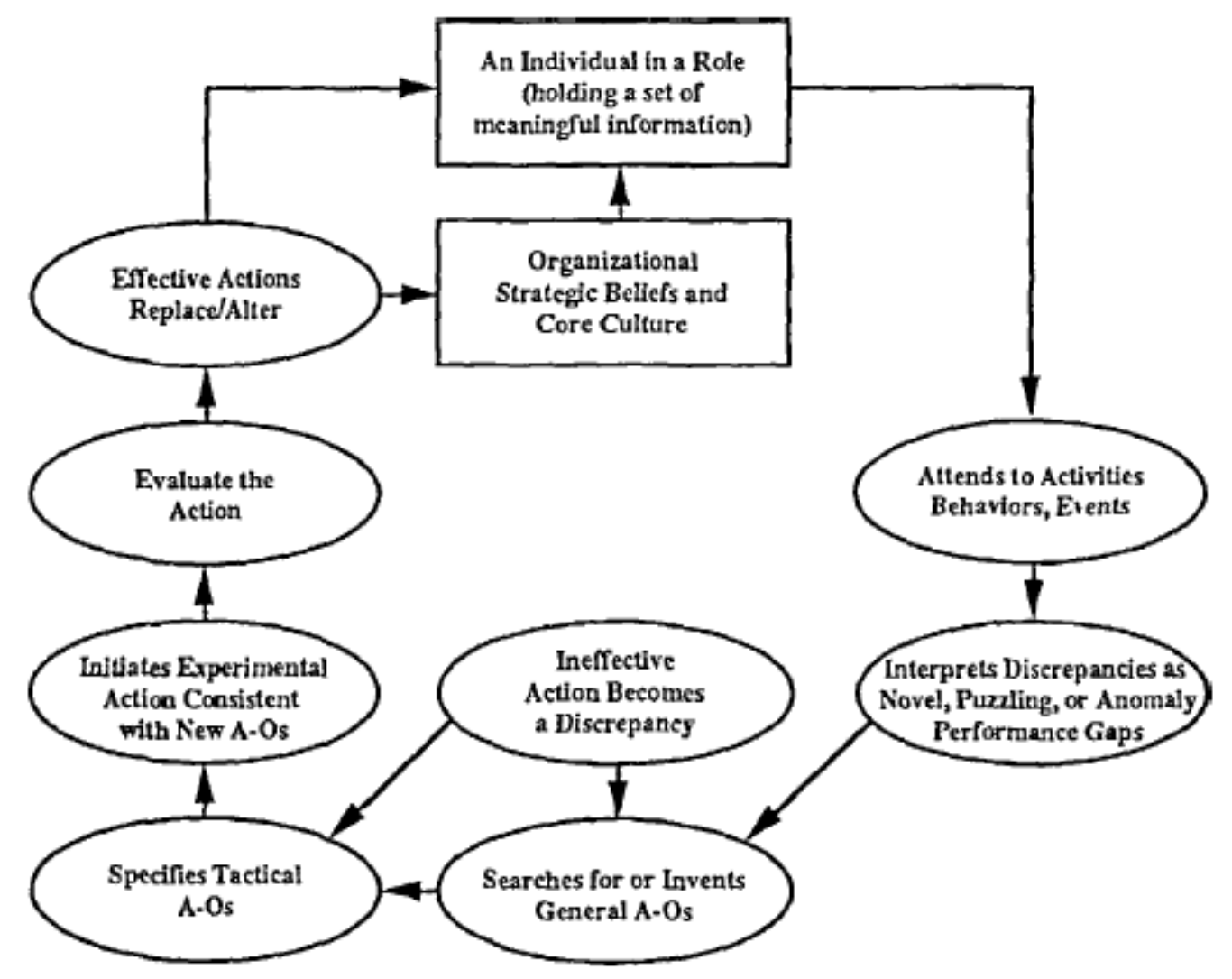

Figure 6. The Organizational Change Cycle 